\title{
Lifestyle factors and site-specific risk of hip fracture in community dwelling older women - a 13-year prospective population-based cohort study
}

Mikko Määttä ${ }^{12^{*}}$, Erkki Terho ${ }^{3}$, Heikki Jokinen ${ }^{1,3}$, Pasi Pulkkinen ${ }^{1}$, Juha Korpelainen ${ }^{4}$, Jorma Heikkinen ${ }^{5}$, Sirkka Keinänen-Kiukaanniemi ${ }^{6,7}$, Timo Jämsä ${ }^{1,8}$ and Raija Korpelainen ${ }^{1,3,6,7}$

\begin{abstract}
Background: Several risk factors are associated to hip fractures. It seems that different hip fracture types have different etiologies. In this study, we evaluated the lifestyle-related risk factors for cervical and trochanteric hip fractures in older women over a 13-year follow-up period.

Methods: The study design was a prospective, population-based study consisting of 1681 women (mean age 72 years). Seventy-three percent $(n=1222)$ participated in the baseline measurements, including medical history, leisure-time physical activity, smoking, and nutrition, along with body anthropometrics and functional mobility. Cox regression was used to identify the independent predictors of cervical and trochanteric hip fractures.

Results: During the follow-up, 49 cervical and 31 trochanteric fractures were recorded. The women with hip fractures were older, taller, and thinner than the women with no fractures $(p<0.05)$. Low functional mobility was an independent predictor of both cervical and trochanteric fractures $(\mathrm{HR}=3.4,95 \% \mathrm{Cl} 1.8-6.6$, and $\mathrm{HR}=5.3$, 95\% Cl 2.5-11.4, respectively). Low baseline physical activity was associated with an increased risk of hip fracture, especially in the cervical region ( $H R=2.5,95 \% \mathrm{Cl} 1.3-4.9)$. A decrease in cervical fracture risk ( $p=0.002)$ was observed with physically active individuals compared to their less active peers (categories: very low or low, moderate, and high). Moderate coffee consumption and hypertension decreased the risk of cervical fractures ( $H R=0.4$, 95\% Cl 0.2-0.8, for both), while smoking was a predisposing factor for trochanteric fractures ( $\mathrm{HR}=3.2,95 \% \mathrm{Cl}$ 1.1-9.3).

Conclusions: Impaired functional mobility, physical inactivity, and low body mass may increase the risk for hip fractures with different effects at the cervical and trochanteric levels.
\end{abstract}

Keywords: Fracture type, Cervical fracture, Trochanteric fracture, Mobility, Physical activity, Risk factors

\section{Background}

The incidence of hip fractures is highest worldwide in Scandinavia [1]. In Finland, the number of hip fractures among older people almost doubled between the early eighties and early nineties, but since then, a decline in hip fracture incidence has been observed both in Finland and around the world [1,2]. The total number of hip

\footnotetext{
* Correspondence: mikko.j.maatta@oulu.fi

'Department of Medical Technology, University of Oulu, PO Box 5000, FI-90014 Oulu, Finland

${ }^{2}$ Infotech Oulu, University of Oulu, PO Box 4500, Fl-90014 Oulu, Finland

Full list of author information is available at the end of the article
}

fractures, however, is likely to rise due to increased longevity [3].

The etiology of hip fractures is multifactorial. The risk factors include female sex and advanced age [4], Caucasian race, [5], low body mass [6], and chronic illnesses [3]. During the last few decades, physical inactivity has been shown to be associated with a greater hip fracture risk among older people [7]. In large, prospective studies, moderate or high leisure time physical activity has been associated with a $28-42 \%$ reduction in hip fracture risk $[6,8-10]$. Physical activity has several advantages, including increased bone strength [11] and decreased risk

\section{Biomed Central}


of falling [12]. During the postmenopausal years, physical activity has been shown to be beneficial for femoral bone density and geometry $[11,13,14]$. High impact exercise is most beneficial for bone formation and for the maintenance of bone mass [15-17]. Long-term lowimpact type of exercise can also decrease bone loss at the proximal femur [14] and can maintain muscle strength and balance, consequently decreasing the risk of falling [18]. Because approximately $90 \%$ of all hip fractures occur as the consequences of falls [19], decreasing the risk of falling is also crucial.

Hip fractures can be divided into two principal groups: cervical (femoral neck) fractures and trochanteric fractures. The different etiologies of these fracture types have been observed [20]. In women, bone geometry and pelvic structure have greater effects on cervical fracture risk, while low bone density is associated with trochanteric fractures. Additionally, women with trochanteric fractures appear to be older than women with cervical fractures. Because the risk factors seem to differ between hip fracture types, different strategies might be needed to obtain optimal results in terms of individual fracture risk assessment and hip fracture prevention.

In a previous study, we reported on the different clinical risk factors for cervical and trochanteric fractures [21]. The aim of the present study was to assess further the lifestyle-related risk factors for hip fractures at different bone sites among older female subjects during an extended 13-year follow-up period.

\section{Methods}

\section{Subjects}

A detailed description of the study population has been previously published [22]. In brief, all 1681 homedwelling women, born between 1924 and 1927 residing in Oulu, Finland, in November 1997, were invited to participate in the study (Figure 1). 1222 women (73\%) out of them were willing to participate. There were no exclusion criteria. The fracture histories of these 1222 women as well as the 459 non-participants were surveyed for 13 years, from Dec. 1, 1997, to Dec. 31, 2010. The procedures of this study were in accordance with the Declaration of Helsinki. The Ethics Committee of the Northern Ostrobothnia Hospital District approved the study design prior to conducting the study. All of the participants provided written informed consent.

\section{Methods}

The study methods have been described in greater detail elsewhere [22]. Postal questionnaires and interviews were used to collect the baseline data regarding lifestyle factors, including a medical history, smoking habits, alcohol and coffee consumption, lifetime leisure-time physical activity, and calcium intake. The clinical examination included anthropometric measurements and an assessment of functional mobility and dynamic balance using the "Timed Up \& Go" (TUG) test [23]. In the TUG test, the subject was timed while she rose from a chair, walked 3 meters, turned, walked back, and sat down again. The TUG test was performed two times consecutively, and the faster time was used in further analyses. In all the tests the subjects were asked to walk at a brisk speed with the help of their standard (if any) walking aid. To assess leisure-time physical activity, a modified Paffenbarger questionnaire was used [24]. The participants were asked to classify themselves according to their frequency and intensity of physical activity during four time periods in their lifespans using a four point scale, corresponding to the ages of 15 years old, 30 years old, and 50 years old and to their current ages. Dairy calcium intake was calculated during the same four time periods of their lifespans [25]. Thirteen-year incident fragility fracture data, regarding hospital-treated fractures in all 1681 women, were collected from hospital discharge registers. A hip fracture was defined as a fracture with ICD-10 (International Classification of Diseases, 10th revision) code between S72.0 and S72.2, S72.0 being classified as a cervical fracture and S72.1 and S72.2 as trochanteric fractures. All of the hip fractures were confirmed manually from medical records to avoid the bias of recording multiple hospitalizations due to a single fracture. The women who only had fractures other than hip fractures were excluded from the final analysis, and subjects with hip fractures were compared to the women with no fractures during the follow up period.

\section{Statistical analysis}

The data were analyzed with PASW Statistics software (Release 18.0.0, IBM Corporation, Route 100, Somers, NY, USA). The participants were classified according to their fracture histories as follows: a) no fracture (NF), b) cervical fracture (Neck Fx), and c) trochanteric fracture (Troch Fx). For the analyses related to leisure exercise exposure, physical activity indices at different ages and a lifetime physical activity index were calculated [22]. The indices were divided into quartiles (very low, low, moderate, and high). Similarly, self-rated mobility was classified into four categories (poor, moderate, good, and very good). Missing calcium intake data for 229 women (18.7\%) were replaced with the study population's mean value. The results of the TUG test were categorized using a cut-off value of 11 seconds, based on a receiver operator characteristics (ROC) analysis. The women with diagnosed heart insufficiency, cerebrovascular disease, or coronary heart disease were aggregated to a cardiovascular disease (CVD) group.

For continuous variables, the differences between the NF and Hip Fx groups were compared using an independent samples $t$-test. For the dichotomous variables, a $X^{2}$-test was 


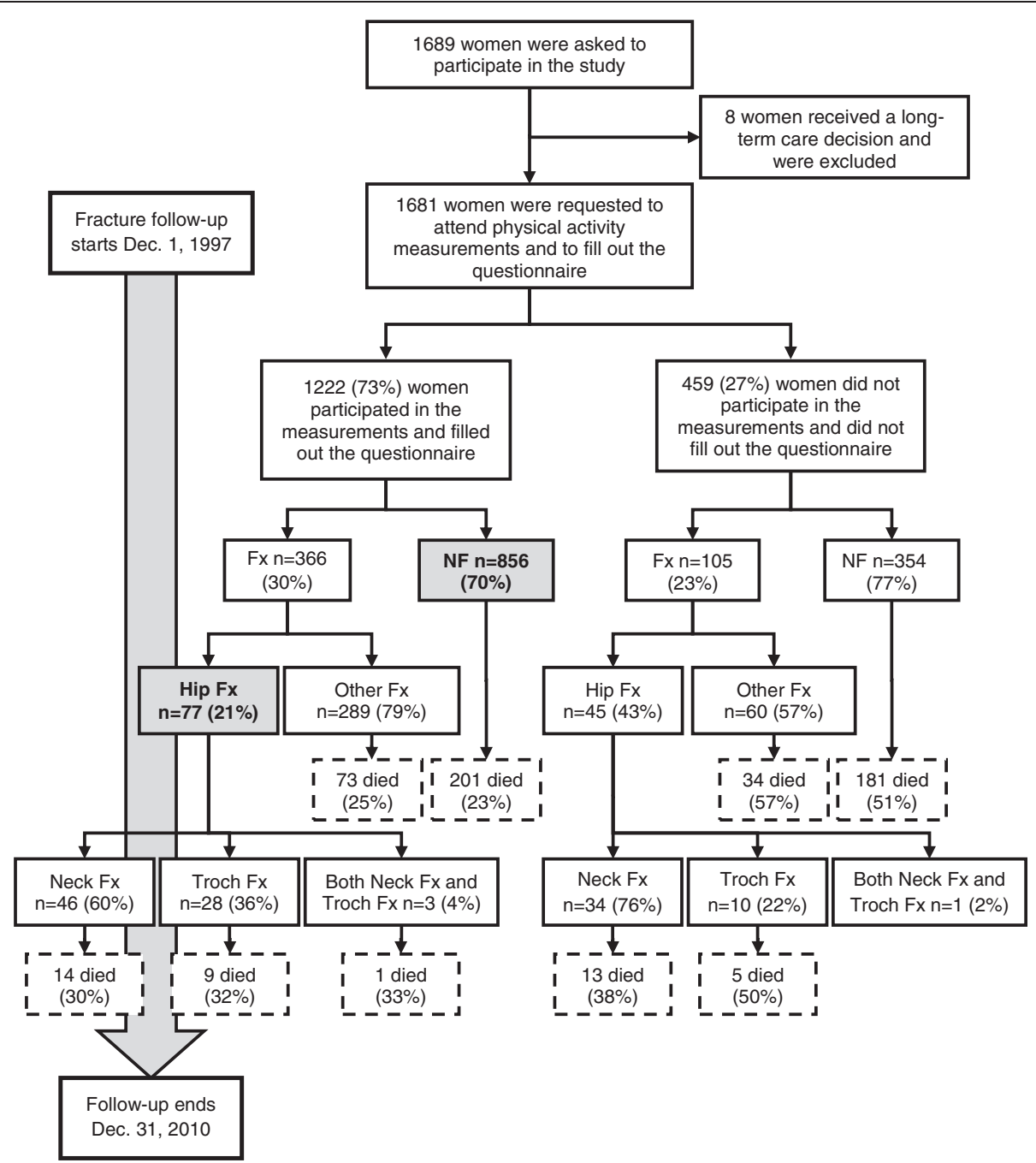

Figure 1 Participant flow. Number of women with and without fractures, as well as deaths, in the study population. NF= subjects with no fractures, Fx = subjects with any fracture, Other Fx= subjects with any fracture other than hip fractures, Hip Fx= subjects with at least one hip fracture, Neck Fx= subjects with a cervical fracture, Troch Fx= subjects with a trochanteric fracture. The subjects included to the final analysis have been highlighted.

used. Similarly, to compare the NF, Neck Fx, and Troch Fx groups for significant differences, one-way ANOVA (post hoc algorithm: Scheffé's test) and an independent samples Kruskal-Wallis method were used for continuous and categorical variables, respectively. When comparing the Neck Fx and Troch Fx groups, the first hip fracture type that occurred was selected for analysis in women with multiple hip fractures. Multiple Cox regression analysis was performed to analyze the relative roles of different variables in hip fracture risk. The variables associated with hip fractures in univariate analyses were selected as covariates to calculate hazard ratios (HR) and 95\% confidence intervals (95\% CI) for different types of hip fractures. In Cox regression analysis, a forward stepwise procedure was used to determine the most predictive variables for hip fracture risk. All regression models were adjusted with age and body mass index (BMI). In stepwise method probability for entry was $\mathrm{p}<0.05$ and for removal $\mathrm{p}<0.10$. All women who did not experience a hip fracture during the follow up period (i.e. the women who died during the follow up period or survived to the end of the follow up period without fractures) were considered as censored. For the regression analysis, the two lowest and two highest physical activity categories were combined. In Kaplan-Meier analysis, a log rank test was used to compare the equality of survival distributions for the different physical activity indices (very low or low vs. moderate vs. high). In all of the tests, $\mathrm{p}$-values less than 0.05 were considered statistically significant.

\section{Results}

During the 13-year follow-up period, 366 subjects (30\%) out of 1222 sustained a bone fracture (Figure 1). Seventy- 
seven subjects (6.3\%) had a hip fracture. Four women out of 77 had two hip fractures, and one woman had three hip fractures. Forty-nine (4.0\%) women had cervical fractures, thirty-one $(2.5 \%)$ had trochanteric fractures, and three $(0.2 \%)$ women had both fracture types. In total, 51 of the fractures were cervical, and 32 fractures were located in the trochanteric region. The final study sample $(n=933)$ consisted of the 77 subjects with hip fracture and the 856 subjects with no fracture.

The mean age of all of the women at the baseline clinical examination was 72 years old. BMI varied between 15 and $46 \mathrm{~kg} / \mathrm{m}^{2}$ (mean $27 \mathrm{~kg} / \mathrm{m}^{2}$ ). The mean weight at baseline was $68 \mathrm{~kg}$ (range 40-113 kg), and the mean height was $159 \mathrm{~cm}$ (range 139-177 cm). The women with hip fractures were older $(p=0.002)$, taller $(p=0.012)$, and thinner $(\mathrm{p}=0.041)$ than the women without fractures (Table 1$)$. During the thirteen-year follow-up, 298 (24.0\%) women died (Figure 1). No differences were observed in death rate between the women with and without hip fractures. Additionally, no differences were observed in calcium intake between the participants with hip fractures and the participants without hip fractures. Fewer women with hip fractures had hypertension.

No differences were observed in lifetime physical activity between the NF and Hip Fx groups nor between the NF, Neck Fx, and Troch Fx groups. However, when comparing physical activity at the age of 72 years (i.e. at baseline), the women with hip fractures were more sedentary than those with no fractures (very low or low vs. moderate or high, $\mathrm{p}=0.016$ ). This difference was also observed between the NF and Neck Fx groups $(p=0.003)$ but not between the $\mathrm{NF}$ and Troch Fx groups $(\mathrm{p}=0.538)$. Similarly, high physical activity at the age of 72 protected from cervical hip fractures compared to the more sedentary women (very low, low, or moderate vs. high, $\mathrm{p}=0.005$ for Neck Fx vs NF, $\mathrm{p}=0.02$ for Troch Fx). The women with hip fractures had lower functional mobility $(\mathrm{p}<0.001)$. Poor performance in TUG test was associated with an increased risk of both fracture types $(\mathrm{p}<0.001)$. There was no difference in functional mobility between the groups of women with different hip fracture types. Self-rated mobility at baseline was not associated with the risk of hip fractures.

Low functional mobility, measured using the TUG test, was the best independent predictor of both cervical and trochanteric fractures in Cox regression analysis $(\mathrm{HR}=3.4,95 \% \mathrm{CI} 1.8-6.6$, and $\mathrm{HR}=5.3,95 \%$ CI 2.5-11.4, respectively) (Table 2). Low physical activity in the beginning of the follow-up period was associated with an increased hip fracture risk, especially with the risk of cervical fractures $(\mathrm{HR}=2.5,95 \% \mathrm{CI} 1.3-4.9)$. There was no relationship between fractures and physical activity earlier in life. Moderate coffee consumption ( $>3$ cups per day) and arterial hypertension decreased the risk of cervical fractures $(\mathrm{HR}=0.4,95 \% \mathrm{CI} 0.2-0.8$, and
$\mathrm{HR}=0.4,95 \%$ CI 0.2-0.8, respectively), whereas daily smoking was a risk factor for trochanteric fractures $(\mathrm{HR}=3.2,95 \%$ CI 1.1-9.3). Low BMI was associated with both fracture types, as well as with a general hip fracture risk (HRs between 0.83 and 0.89). Neither estrogen treatment nor specific osteoporosis medication at baseline was associated with the future risk of hip fractures.

A significant difference between the baseline physical activity categories (very low or low vs. moderate vs. high) was found in Kaplan-Meier survival analysis, with the exception of trochanteric fractures (Figure 2). High physical activity protected the women from hip fractures (p-values of log rank tests: Hip Fx $\mathrm{p}=0.012$; Neck Fx $\mathrm{p}=0.002$; Troch Fx $\mathrm{p}=0.578)$. After adjusting the model for the change in BMI between 1997 and 2004, the protective effect of physical activity against cervical hip fractures, but not all hip fractures, remained $(\mathrm{p}=0.017)$.

\section{Discussion}

In this prospective, population-based, 13-year cohort study, low physical activity was a strong risk factor for cervical, but not for trochanteric, hip fractures. Additionally, functional mobility, measured with the TUG test, and low BMI were associated with the risk of both hip fracture types. Other clinical factors appeared to differ between the hip fracture sites: hypertension and coffee consumption of more than three cups per day decreased the risk of cervical hip fractures, while daily smoking increased the risk of trochanteric hip fractures.

Physical activity helps to maintain muscle strength and mobility and thus prevent falls in older people [18]. In contrast, a more active lifestyle has been shown to increase the incidence of nonsyncope falls and related traumas, e.g., wrist fractures $[14,26]$. Our results showed that the women with high physical activity at baseline had a lower risk of future hip fractures (especially the risk of cervical fractures) than women with moderate or low activity. A similar dose-response relationship has been reported in both male [27] and female populations $[6,28]$. Based on our results, regardless of earlier lifetime physical activity, an active lifestyle in the postmenopausal years decreases the fracture risk. Both Feskanich et al. [28] and Michaëlsson et al. [27] reported that by increasing physical activity during the lifespan, the fracture risk could be diminished, whereas Høidrup et al. [10] reported that increments in physical activity during follow-up did not influence the risk of hip fractures. In our study, no longitudinal data on physical activity during the follow-up period were available.

Baseline physical activity was associated with cervical, but not with trochanteric, fractures in our study population. This finding might indicate an association between physical activity and femoral geometry. Previously, it has been shown that bone geometry is associated with 
Table 1 Baseline characteristics of the women with and without hip fractures $(n=933)$

\begin{tabular}{|c|c|c|c|c|c|c|c|c|c|}
\hline & \multirow{2}{*}{$\begin{array}{l}N F \\
n=856\end{array}$} & \multirow{2}{*}{$\begin{array}{l}\text { Hip Fx } \\
\mathrm{n}=77\end{array}$} & \multirow{2}{*}{$\begin{array}{l}\text { Neck Fx } \\
n=49\end{array}$} & \multirow{2}{*}{$\begin{array}{l}\text { Troch Fx } \\
\mathrm{n}=31\end{array}$} & \multicolumn{5}{|l|}{ p-values } \\
\hline & & & & & $\begin{array}{l}\text { NF vs. } \\
\text { Hip Fx }\end{array}$ & $\begin{array}{l}\text { Between } \\
\text { groups }\end{array}$ & $\begin{array}{l}\text { NF vs. } \\
\text { Neck Fx }\end{array}$ & $\begin{array}{l}\text { NF vs. } \\
\text { Troch Fx }\end{array}$ & $\begin{array}{l}\text { Neck Fx vs. } \\
\text { Troch Fx }\end{array}$ \\
\hline Age (yrs) & $71.3(1.1)$ & $71.7(1.1)$ & $71.5(1.1)$ & $72.1(0.9)$ & 0.002 & $<0.001$ & 0.668 & $<0.001$ & 0.031 \\
\hline Age at $1^{\text {st }}$ fracture (yrs) & - & $79.4(3.9)$ & $79.6(3.8)$ & $79.0(4.1)$ & - & 0.521 & - & - & 0.521 \\
\hline Weight (kg) & $68.9(10.9)$ & $66.3(11.8)$ & $67.2(12.5)$ & $64.5(10.2)$ & 0.041 & 0.076 & 0.579 & 0.121 & 0.611 \\
\hline Height (cm) & $157.9(5.7)$ & $159.6(5.2)$ & $159.8(5.1)$ & $159.3(5.1)$ & 0.012 & 0.041 & 0.082 & 0.438 & 0.930 \\
\hline BMI $\left(\mathrm{kg} / \mathrm{m}^{2}\right)$ & $27.7(4.1)$ & $25.9(3.8)$ & $26.2(4.0)$ & $25.3(3.2)$ & $<0.001$ & 0.001 & 0.046 & 0.008 & 0.673 \\
\hline Calcium intake / day (mg) & $809.1(345.9)$ & $819.5(353.9)$ & $857.3(375.8)$ & $752.7(294.4)$ & 0.801 & 0.413 & 0.618 & 0.693 & 0.426 \\
\hline Timed Up \& Go (s) & $11.1(3.4)$ & $13.3(4.9)$ & $12.9(4.6)$ & $14.4(5.8)$ & $<0.001$ & $<0.001$ & 0.006 & $<0.001$ & 0.360 \\
\hline \multirow[t]{2}{*}{ Daily smoking, yes vs. no, n (\%) } & $42(4.9)$ & $7(9.1)$ & $4(8.2)$ & $4(12.9)$ & 0.115 & 0.074 & 0.313 & 0.049 & 0.766 \\
\hline & $814(95.1)$ & $70(90.9)$ & $45(91.8$ & $27(87.1)$ & & & & & \\
\hline \multirow[t]{2}{*}{ Corticosteroids, yes vs. no, n (\%) } & $13(1.5)$ & $1(1.3)$ & $0(0.0)$ & $1(3.2)$ & 0.879 & 0.669 & 0.358 & 0.454 & 0.195 \\
\hline & $843(98.5)$ & $76(98.7)$ & $49(100.0)$ & $30(96.8)$ & & & & & \\
\hline \multirow[t]{2}{*}{ Daily alcohol use, yes vs. no, n (\%) } & $8(0.9)$ & $1(1.3)$ & $1(2.0)$ & $0(0.0)$ & 0.754 & 0.798 & 0.448 & 0.589 & 0.434 \\
\hline & $848(99.1)$ & $76(98.7)$ & $48(98.0)$ & $31(100.0)$ & & & & & \\
\hline \multirow[t]{2}{*}{ Calcium intake $<800 \mathrm{mg} /$ day vs. more, $\mathrm{n}(\%)$} & $364(42.5)$ & $32(41.6)$ & $18(36.7)$ & $15(48.4)$ & 0.870 & 0.723 & 0.425 & 0.517 & 0.353 \\
\hline & $492(57.5)$ & $45(58.4)$ & $31(63.3)$ & $16(51.6)$ & & & & & \\
\hline \multirow[t]{2}{*}{ Rheumatoid arthritis, yes vs. no, n (\%) } & $48(5.6)$ & $7(9.1)$ & $3(6.1)$ & $4(12.9)$ & 0.214 & 0.273 & 0.879 & 0.089 & 0.265 \\
\hline & $808(49.4)$ & $70(90.9)$ & $46(93.9)$ & $27(87.1)$ & & & & & \\
\hline \multirow[t]{2}{*}{ Estrogen use, yes vs. no, n (\%) } & $39(4.6)$ & $5(6.5)$ & $5(10.2)$ & $2(6.5)$ & 0.442 & 0.084 & 0.074 & 0.621 & 0.072 \\
\hline & $817(95.4)$ & $72(93.5)$ & $44(89.8)$ & $29(93.5)$ & & & & & \\
\hline \multirow[t]{2}{*}{ Osteoporosis medication, yes vs. no, n (\%) } & $29(3.4)$ & $3(3.9)$ & $2(4.1)$ & $1(3.2)$ & 0.814 & 0.973 & 0.795 & 0.961 & 0.875 \\
\hline & $827(96.6)$ & $74(96.1)$ & $47(95.9)$ & $30(96.8)$ & & & & & \\
\hline \multirow[t]{2}{*}{ Coffee usage > 3 cups / day vs. less, n (\%) } & $384(44.9)$ & $30(39.0)$ & $14(28.6)$ & $16(51.6)$ & 0.310 & 0.035 & 0.019 & 0.404 & 0.016 \\
\hline & $428(50.0)$ & $43(55.8)$ & $33(67.3)$ & $13(41.9)$ & & & & & \\
\hline \multirow[t]{2}{*}{ Diabetes, yes vs. no, n (\%) } & $112(13.1)$ & $15(19.5)$ & $9(18.4)$ & $7(22.6)$ & 0.117 & 0.361 & 0.291 & 0.128 & 0.835 \\
\hline & $744(86.9)$ & $62(80.5)$ & $40(81.6)$ & $24(77.4)$ & & & & & \\
\hline \multirow[t]{2}{*}{ Hypertension, yes vs. no, n (\%) } & $315(36.8)$ & $19(24.7)$ & $11(22.4)$ & $10(32.3)$ & 0.034 & 0.043 & 0.042 & 0.606 & 0.314 \\
\hline & $541(63.2)$ & $58(75.3)$ & $38(77.6)$ & $21(67.7)$ & & & & & \\
\hline \multirow[t]{2}{*}{ CVD, yes vs. no, n (\%) } & $299(63.2)$ & $26(33.8)$ & 15 (30.6) & $13(41.9)$ & 0.837 & 0.483 & 0.537 & 0.422 & 0.272 \\
\hline & $557(34.9)$ & 51 (66.2) & 34 (69.4) & 18 (58.1) & & & & & \\
\hline
\end{tabular}

Values are the means (SD) unless otherwise specified. Student's $t$-test (NF vs. Hip Fx) and ANOVA (Scheffé's post hoc test (NF vs. Neck Fx vs. Troch Fx)) were used with scalar variables, and a $x^{2}$ test and an independent samples Kruskal-Wallis test with categorical variables were used to calculate differences between groups. NF $=$ subjects with no fractures, Hip $F x=$ subjects with a hip fracture, Neck Fx $=$ subjects with a cervical fracture, Troch $\mathrm{Fx}=$ subjects with a trochanteric fracture, $\mathrm{BMI}=$ body mass index, $\mathrm{CVD}=$ cardiovascular diseases, $\mathrm{SD}=$ standard deviation. Numbers do not match due to missing values. 
Table 2 Cox regression models for having any hip fractures, cervical fractures, and trochanteric fractures in a population-based sample of older women

\begin{tabular}{|c|c|c|c|c|c|}
\hline & $\beta$ & SE & HR & $95 \% \mathrm{Cl}$ for $\mathrm{HR}$ & Covariate $p$-value \\
\hline \multicolumn{6}{|l|}{ Any hip fractures ${ }^{a)}$} \\
\hline Age / 1 year increment & 0.257 & 0.113 & 1.29 & $1.04-1.61$ & 0.022 \\
\hline $\mathrm{BMl} / 1$ unit increment & -0.144 & 0.034 & 0.87 & $0.81-0.93$ & $<0.001$ \\
\hline TUG $\geq 11 \mathrm{~s}$ vs. less (referent) & 1.201 & 0.258 & 3.32 & $2.01-5.51$ & $<0.001$ \\
\hline Low physical activity vs. moderate to high (referent) & 0.697 & 0.259 & 2.01 & $1.21-3.34$ & 0.007 \\
\hline Hypertension vs. none (referent) & -0.627 & 0.306 & 0.53 & $0.29-0.97$ & 0.040 \\
\hline \multicolumn{6}{|l|}{ Cervical fractures ${ }^{b)}$} \\
\hline $\mathrm{BMI} / 1$ unit increment & -0.119 & 0.042 & 0.89 & $0.82-0.96$ & 0.004 \\
\hline TUG $\geq 11 \mathrm{~s}$ vs. less (referent) & 1.226 & 0.333 & 3.41 & $1.77-6.55$ & $<0.001$ \\
\hline Low physical activity vs. moderate to high (referent) & 0.910 & 0.344 & 2.48 & $1.27-4.87$ & 0.008 \\
\hline Hypertension vs. none (referent) & -1.030 & 0.426 & 0.36 & $0.16-0.82$ & 0.016 \\
\hline Coffee consumption > 3 cups / day vs. less (referent) & -0.944 & 0.358 & 0.39 & $0.19-0.79$ & 0.008 \\
\hline \multicolumn{6}{|l|}{ Trochanteric fractures ${ }^{c}$ ) } \\
\hline Age / 1 year increment & 0.636 & 0.183 & 1.89 & $1.32-2.70$ & 0.001 \\
\hline BMl / 1 unit increment & -0.186 & 0.051 & 0.83 & $0.75-0.92$ & $<0.001$ \\
\hline TUG $\geq 11 \mathrm{~s}$ vs. less (referent) & 1.664 & 0.393 & 5.28 & $2.45-11.41$ & $<0.001$ \\
\hline Daily smoking vs. no (referent) & 1.165 & 0.543 & 3.21 & $1.11-9.29$ & 0.032 \\
\hline
\end{tabular}

Hazard ratios (HR) are calculated compared to the no fracture group. In the cervical fracture model, age was also added as a covariate but was not included in the final model. $\beta=$ regression coefficient, $\mathrm{SE}=$ standard error of $\beta, \mathrm{Cl}=$ confidence interval, $\mathrm{BMI}=$ body mass index, TUG = "Timed Up \& Go" test. Due to missing values, the number of subjects were ${ }^{\text {a) }} \mathrm{Fx} n=66, N F n=775,{ }^{\text {b) }} \mathrm{Fx} n=39, N F n=740$, and ${ }^{\text {c) }} \mathrm{Fx} n=31, N F n=856$.

cervical fracture risk, while bone density is more strongly related to the risk of trochanteric fractures [29]. Furthermore, it has been shown that mechanical loading is a strong external determinant of the structure and concomitant strength of the femoral neck [30]. Therefore, this finding may arise from the structural weakening of the femoral neck caused by a low physical activity level. In particular, the thinning with age of the superolateral femoral neck cortex leads to the loss of elastic stability due to under loading of this site, exposing it to local buckling of the cortex [31,32]. Based on the current results, it can be assumed that this structural weakening may accelerate in individuals with low levels of physical activity, thus increasing the risk of femoral neck failure.

In this study, we evaluated functional mobility using the "Timed Up \& Go" (TUG) test. The TUG test is easy to perform and reproducible, and it is a sensitive and specific measure for evaluating fall risks [23,33]. In our study, 11 seconds was selected as the threshold value for the TUG test based on receiver operator characteristics (ROC) analysis. Thirty-three percent of the subjects took more than eleven seconds to complete the test. We found low functional mobility to be a risk factor for both types of hip fractures. Similar results with a similar population were reported earlier for general hip fracture risks among subjects with slow TUG performances [34]. In some studies, walking speed and repeated rising from a chair have been used as alternatives to the TUG test to assess mobility and neuromuscular function. In a study by Fox et al. [35], walking speed was associated with both hip fracture types, but the ability to complete five chair stands was not associated with either. In contrast, Cummings et al. [8] reported that subjects unable to rise repeatedly from a chair had a higher risk of hip fractures. Because functional mobility is easy to assess, it should be routinely evaluated to screen for individuals at high risk for fragility hip fractures.

The role of arterial hypertension as a risk factor for hip fractures is somewhat controversial. Hypertension alone has been shown to increase fracture risks by affecting calcium metabolism [36], as well as by increasing the risk of falling due to reduced baroreflex sensitivity or hypotension [37]. In the present study, hypertension was found to be protective against hip fractures. This may be due to the use of thiazides as diuretic medication for hypertension. Thiazide diuretics have been reported to have positive effects, in terms of bone strength [38], by reducing urinary calcium excretion and helping to maintain calcium balance [39], and by inhibiting bone resorption by means of inducing metabolic alkalosis [40].

Multiple studies have indicated that smoking increases fracture risks in both women and men [41,42]. Numerous reasons for increased fracture risks have been suggested. These reasons include direct toxic effects on the 


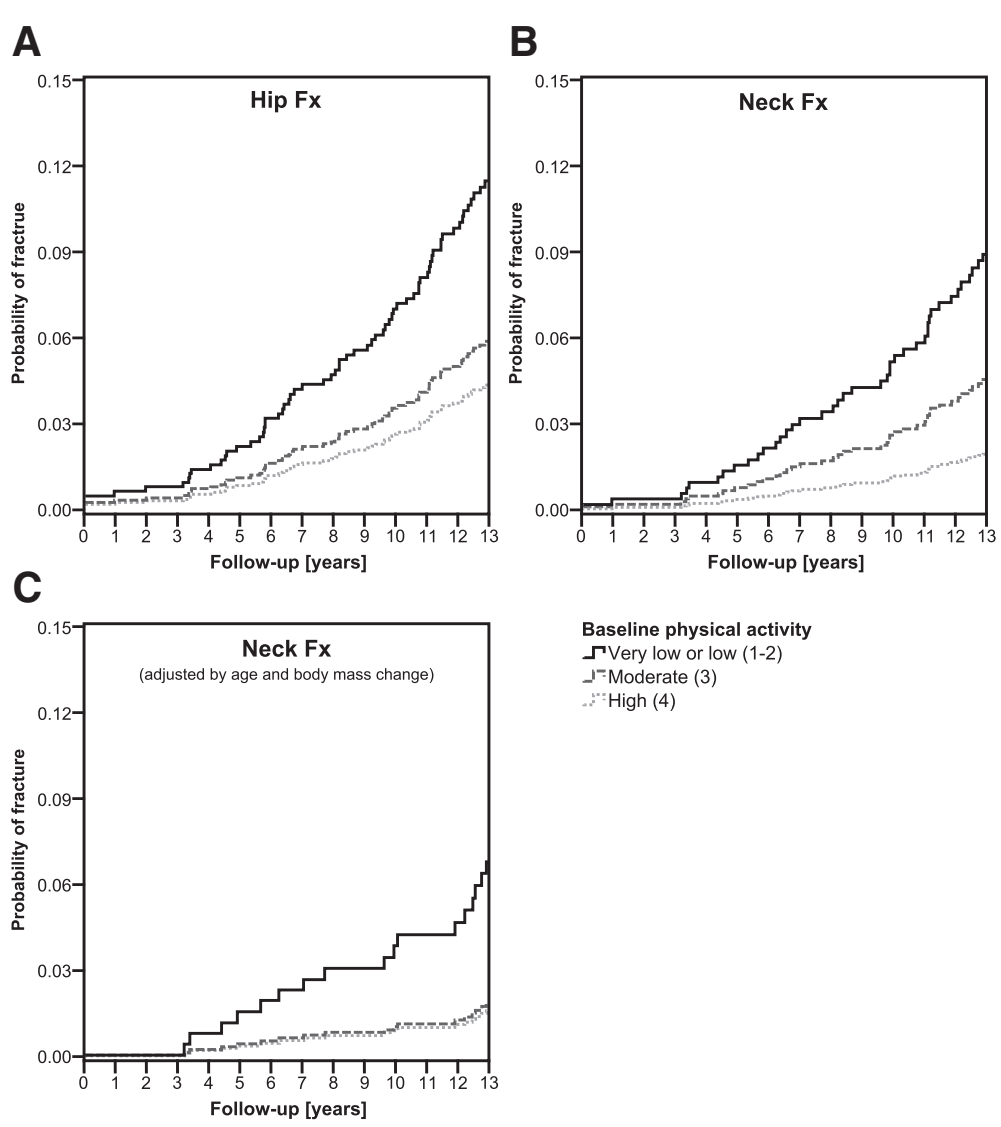

Figure 2 Probability of (A) any hip fracture and (B) cervical fracture with different baseline physical activity indices (very low or low, moderate, and high) adjusted by age and body mass index at baseline, and of (C) cervical fracture after adjustment for age and change in body weight between baseline and 2004 (NF $n=488$, Neck Fx $n=17$ ).

bones due to exposure to nicotine, reduction of calcium absorption, transient increases in cortisol levels after smoking, lower BMI, and an increased risk of falling in smokers, as well as lower estrogen levels and earlier menopause [43]. In our population, there were only seven fracture subjects who declared at baseline that they smoked daily. The observed increase in trochanteric fracture risk may be due to the above-mentioned reasons, but the ultimate reason cannot be determined. Because the trochanteric region is rich in trabecular bone, the increased risk might occur because tobacco affects this metabolically active region. However, the small number of fractures limits the statistical power of this finding. Nevertheless, our results suggest an increased risk of trochanteric fractures among smokers and are in line with earlier studies.

Our results suggest that coffee consumption of more than 3 cups per day may prevent cervical hip fractures. However, excessive coffee drinking has been reported to be associated with an increased hip fracture risk $[8,21]$. In a recent review by Higdon and Frei [44], the effects of coffee on bone density and hip fracture risk were discussed. Caffeine affects calcium absorption and leads to a slightly negative calcium balance in individuals with inadequate calcium intake. Moderate coffee consumption has some other health benefits [44], which together with our finding support moderate coffee consumption.

We found no differences in hip fracture risks between women who had received estrogen treatment or taken osteoporosis medication at baseline compared to women who did not receive estrogen treatment. One possible explanation for this result is that the new-generation drugs for osteoporosis were not available earlier in the study period, and very few women had taken medication for osteoporosis. Furthermore, population studies have observed a reduced risk of hip fractures with postmenopausal hormone use among sedentary women but not among physically active women [10,27]. However, we did not observe this type of trend. This finding might be due to the low number of fractures, especially among women taking estrogen medication. The postal questionnaires also included questions concerning asthma and incontinence. These conditions, however, showed no effects on the hip fracture risk in this population. 
The strengths of this study were its population-based, prospective nature and the long follow-up period. The target population was a homogenous, stable, and representative sample of older Finnish women, obtained from the National Population Register of Finland, which provides $100 \%$ coverage. This study also has some limitations. Because of the population-based nature of the present study, the results can be generalized to older Caucasian women. However, there might be some selection bias because the 459 women (27.3\% of the total cohort of 1681 women ) who neither replied to the postal questionnaires nor participated in the clinical examination were more fragile, with a higher hip fracture rate $(9.8 \%$ vs. $6.3 \%)$ and higher mortality $(50.8 \%$ vs. $25.1 \%)$ than the participants. According to Finnish National Institute for Health and Welfare, in year 2009, 6085 hip fractures occurred in Finland. The age-standardized hip fracture incidence of 293 fractures $/ 100,000$ persons among Finnish women has recently been reported [45]. Thus, the results may not be suitable for generalization to very frail or institutionalized women. Unfortunately, other health data were not available here for the nonparticipants. The number of hip fractures was limited. In 1222 women, we observed 49 cervical and 31 trochanteric fractures. It also should be noted that all of the clinical and questionnaire data, excluding the fracture data, were collected only at baseline and were not repeatedly collected during the follow-up. In addition, no hip or spine DXA data were available.

\section{Conclusions}

In conclusion, the differences between cervical and trochanteric fracture risk factors were observed. Low baseline physical activity and impaired functional mobility, along with low BMI, increased the risk, whereas moderate coffee consumption and arterial hypertension decreased the risk of cervical fractures. Impaired functional mobility, smoking, advanced age, and low BMI predicted trochanteric hip fractures. Further studies on the effect of impaired mobility and low physical activity are needed to confirm their independent role in hip fracture risk stratification.

\section{Abbreviations}

HR: Hazard Ratio; Cl: Confidence Interval; TUG: Timed Up \& Go -test; ICD10: International Classification of Diseases 10th revision; ROC: Receiver Operator Characteristics; CVD: Cardiovascular disease; ANOVA: Analysis of variance; BMI: Body Mass Index; $\beta$ : Regression coefficient; SE: Standard Error of regression coefficient.
}

\section{Competing interests}

The authors declare that they have no competing interests.

\section{Authors' contributions}

MM participated in the fracture data collection, carried out the main analyses, and wrote the main parts of the manuscript. ET and $\mathrm{HJ}$ participated in the fracture data collection and analyses of the data. PP made a contribution to the design of the study and revising the manuscript $\mathrm{JK}, \mathrm{JH}$, and SK-K participated in conception and design of the study and $\mathrm{JH}$ also participated in data collection. TJ and RK participated in conception and design and made substantial contributions to the manuscript. RK also participated significantly to data collection. All authors have read, revised, and given their final approval of the version to be published.

\section{Acknowledgments}

Funding/Support: This study was funded by the Finnish Ministry of Education, the Finnish Funding Agency for Technology and Innovation, the Academy of Finland, the Finnish Cultural Foundation, the Juho Vainio Foundation, Oulu University Hospital, and the Orion-Farmos Research Foundation. The authors thank Mr. Risto Bloigu, M.Sc., for his statistical assistance.

\section{Author details}

'Department of Medical Technology, University of Oulu, PO Box 5000, FI-90014 Oulu, Finland. ${ }^{2}$ Infotech Oulu, University of Oulu, PO Box 4500, Fl-90014 Oulu, Finland. ${ }^{3}$ Department of Sports and Exercise Medicine, Oulu Deaconess Institute, Kajaaninkatu 17, FI-90100 Oulu, Finland. ${ }^{4}$ Oulu University Hospital, Kajaanintie 50, Fl-90029 Oulu, Finland. ${ }^{5}$ Osteoporosis Clinic, Oulu Deaconess Institute, Albertinkatu 16, Fl-90100 Oulu, Finland. ${ }^{6}$ Institute of Health Sciences, University of Oulu, PO Box 5000, FI-90014 Oulu, Finland. 7Unit of General Practice, Oulu University Hospital, Kajaanintie 50, Fl-90029 Oulu, Finland. ${ }^{8}$ Department of Diagnostic Radiology, Oulu University Hospital, Kajaanintie 50, FI-90029 Oulu, Finland.

Received: 4 April 2012 Accepted: 13 September 2012

Published: 14 September 2012

\section{References}

1. Cooper C, Cole ZA, Holroyd CR, Earl SC, Harvey NC, Dennison EM, Melton L, Cummings SR, Kanis JA, IOF CSA Working Group on Fracture Epidemiology: Secular trends in the incidence of hip and other osteoporotic fractures. Osteoporos Int 2011, 22(5):1277-1288.

2. Kannus P, Niemi S, Parkkari J, Palvanen M, Vuori I, Järvinen M: Nationwide decline in incidence of hip fracture. J Bone Miner Res 2006, 21(12):1836-1838.

3. Marks R: Physical activity and hip fracture disability: a review. J Aging Res 2011, 2011:741918.

4. Seeman E: Pathogenesis of bone fragility in women and men. Lancet 2002, 359(9320):1841-1850

5. Cauley JA: Defining ethnic and racial differences in osteoporosis and fragility fractures. Clin Orthop Relat Res 2011, 469(7):1891-1899.

6. Armstrong ME, Spencer EA, Cairns BJ, Banks E, Pirie K, Green J, Wright FL, Reeves GK, Beral V, the Million Women Study Collaborators: Body mass index and physical activity in relation to the incidence of hip fracture in postmenopausal women. J Bone Miner Res 2011, 26(6):1330-1338.

7. Moayyeri A: The association between physical activity and osteoporotic fractures: a review of the evidence and implications for future research. Ann Epidemiol 2008, 18(11):827-835.

8. Cummings SR, Nevitt MC, Browner WS, Stone K, Fox KM, Ensrud KE, Cauley J, Black D, Vogt TM: Risk factors for hip fracture in white women Study of Osteoporotic Fractures Research Group. N Engl J Med 1995, 332(12):767-773.

9. Gregg EW, Cauley JA, Seeley DG, Ensrud KE, Bauer DC: Physical activity and osteoporotic fracture risk in older women Study of Osteoporotic Fractures Research Group. Ann Intern Med 1998, 129(2):81-88.

10. Høidrup S, Sørensen TI, Strøger U, Lauritzen JB, Schroll M, Grønbæk M: Leisure-time physical activity levels and changes in relation to risk of hip fracture in men and women. Am J Epidemiol 2001, 154(1):60-68.

11. Hamilton CJ, Swan VJ, Jamal SA: The effects of exercise and physical activity participation on bone mass and geometry in postmenopausal women: a systematic review of pQCT studies. Osteoporos Int 2010, 21(1):11-23.

12. Sherrington C, Tiedemann A, Fairhall N, Close JC, Lord SR: Exercise to prevent falls in older adults: an updated meta-analysis and best practice recommendations. N S W Public Health Bull 2011, 22(3-4):78-83.

13. Uusi-Rasi K, Sievänen H, Pasanen M, Beck TJ, Kannus P: Influence of calcium intake and physical activity on proximal femur bone mass and structure among pre- and postmenopausal women. A 10-year prospective study. Calcif Tissue Int 2008, 82(3):171-181.

14. Rikkonen $T$, Salovaara $K$, Sirola J, Kärkkäinen $M$, Tuppurainen $M$, Jurvelin J, Honkanen R, Alhava E, Kröger H: Physical activity slows femoral bone loss 
but promotes wrist fractures in postmenopausal women: a 15-year follow-up of the OSTPRE study. J Bone Miner Res 2010, 25(11):2332-2340.

15. Wolff I, van Croonenborg JJ, Kemper HC, Kostense PJ, Twisk JW: The effect of exercise training programs on bone mass: a meta-analysis of published controlled trials in pre- and postmenopausal women. Osteoporos Int 1999, 9(1):1-12.

16. Vainionpää $A$, Korpelainen $R$, Leppäluoto J, Jämsä $T$ : Effects of high-impact exercise on bone mineral density: a randomized controlled trial in premenopausal women. Osteoporos Int 2005, 16(2):191-197.

17. Martyn-St James M, Carroll S: Effects of different impact exercise modalities on bone mineral density in premenopausal women: a metaanalysis. J Bone Miner Metab 2010, 28(3):251-267.

18. Korpelainen $\mathrm{R}$, Keinänen-Kiukaanniemi $\mathrm{S}$, Heikkinen J, Väänänen $\mathrm{K}$, Korpelainen J: Effect of exercise on extraskeletal risk factors for hip fractures in elderly women with low BMD: a population-based randomized controlled trial. J Bone Miner Res 2006, 21(5):772-779.

19. Tinetti ME: Clinical practice Preventing falls in elderly persons. N Engl J Med 2003, 348(1):42-49.

20. Pulkkinen $P$, Glüer CC, Jämsä T: Investigation of differences between hip fracture types: a worthy strategy for improved risk assessment and fracture prevention. Bone 2011, 49(4):600-604

21. Jokinen $H$, Pulkkinen $P$, Korpelainen J, Heikkinen J, Keinänen-Kiukaanniemi S, Jämsä T, Korpelainen R: Risk factors for cervical and trochanteric hip fractures in elderly women: a population-based 10-year follow-up study. Calcif Tissue Int 2010, 87(1):44-51.

22. Korpelainen R, Korpelainen J, Heikkinen J, Väänänen K, KeinänenKiukaanniemi S: Lifestyle factors are associated with osteoporosis in lean women but not in normal and overweight women: a population-based cohort study of 1222 women. Osteoporos Int 2003, 14(1):34-43.

23. Podsiadlo D, Richardson S: The timed "Up \& Go": a test of basic functional mobility for frail elderly persons. J Am Geriatr Soc 1991, 39(2):142-148.

24. Greendale GA, Barrett-Connor E, Edelstein S, Ingles S, Haile R: Lifetime leisure exercise and osteoporosis The Rancho Bernardo study. Am J Epidemiol 1995, 141(10):951-959.

25. Tuppurainen M, Kröger H, Saarikoski S, Honkanen R, Alhava E: The effect of previous oral contraceptive use on bone mineral density in perimenopausal women. Osteoporos Int 1994, 4(2):93-98.

26. Faulkner KA, Cauley JA, Studenski SA, Landsittel DP, Cummings SR, Ensrud KE, Donaldson MG, Nevitt MC, Study of Osteoporotic Fractures Research Group: Lifestyle predicts falls independent of physical risk factors. Osteoporos Int 2009, 20(12):2025-2034.

27. Michaëlsson K, Olofsson H, Jensevik K, Larsson S, Mallmin H, Berglund L, Vessby $\mathrm{B}$, Melhus $\mathrm{H}$ : Leisure physical activity and the risk of fracture in men. PLoS Med 2007, 4(6):e199.

28. Feskanich D, Willett W, Colditz G: Walking and leisure-time activity and risk of hip fracture in postmenopausal women. JAMA 2002, 288(18):2300-2306.

29. Pulkkinen $P$, Partanen J, Jalovaara $P$, Jämsä $T$ : Combination of bone mineral density and upper femur geometry improves the prediction of hip fracture. Osteoporos Int 2004, 15(4):274-280.

30. Nikander R, Kannus P, Dastidar P, Hannula M, Harrison L, Cervinka T, Narra NG, Aktour R, Arola T, Eskola H, Soimakallio S, Heinonen A, Hyttinen J, Sievänen H: Targeted exercises against hip fragility. Osteoporos Int 2009, 20(8):1321-1328.

31. Mayhew PM, Thomas CD, Clement JG, Loveridge N, Beck TJ, Bonfield W, Burgoyne CJ, Reeve J: Relation between age, femoral neck cortical stability, and hip fracture risk. Lancet 2005, 366(9480):129-135.

32. Rivadeneira F, Zillikens MC, De Laet CE, Hofman A, Uitterlinden AG, Beck TJ, Pols HA: Femoral neck BMD is a strong predictor of hip fracture susceptibility in elderly men and women because it detects cortical bone instability: the Rotterdam Study. J Bone Miner Res 2007, 22(11):1781-1790.

33. Shumway-Cook A, Brauer S, Woollacott M: Predicting the probability for falls in community-dwelling older adults using the Timed Up \& Go Test. Phys Ther 2000, 80(9):896-903

34. Zhu K, Devine A, Lewis JR, Dhaliwal SS, Prince RL: 'Timed up and go' test and bone mineral density measurement for fracture prediction. Arch Intern Med 2011, 171(18):1655-1661.

35. Fox KM, Cummings SR, Williams E, Stone K, Study of Osteoporotic Fractures: Femoral neck and intertrochanteric fractures have different risk factors: a prospective study. Osteoporos Int 2000, 11(12):1018-1023.
36. Cappuccio FP, Kalaitzidis R, Duneclift S, Eastwood JB: Unravelling the links between calcium excretion, salt intake, hypertension, kidney stones and bone metabolism. J Nephrol 2000, 13(3):169-177.

37. Harrington F, Murray A, Ford GA: Relationship of baroreflex sensitivity and blood pressure in an older population. J Hypertens 2000, 18(11):1629-1633.

38. Schoofs MW, van der Klift M, Hofman A, de Laet CE, Herings RM, Stijnen T, Pols HA, Stricker BH: Thiazide diuretics and the risk for hip fracture. Ann Intern Med 2003, 139(6):476-482.

39. Adams JS, Song CF, Kantorovich V: Rapid recovery of bone mass in hypercalciuric, osteoporotic men treated with hydrochlorothiazide. Ann Intern Med 1999, 130(8):658-660.

40. Peh CA, Horowitz M, Wishart JM, Need AG, Morris HA, Nordin BE: The effect of chlorothiazide on bone-related biochemical variables in normal postmenopausal women. J Am Geriatr Soc 1993, 41(5):513-516.

41. Baron JA, Farahmand BY, Weiderpass E, Michaelsson K, Alberts A, Persson I, Ljunghall S: Cigarette smoking, alcohol consumption, and risk of hip fracture in women. Arch Intern Med 2001, 161(7):983-988.

42. Jutberger $H$, Lorentzon $M$, Barrett-Connor $E$, Johansson $H$, Kanis JA, Ljunggren Ö, Karlsson MK, Rosengren BE, Redlund-Johnell I, Orwoll E, Ohlsson C, Mellström D: Smoking predicts incident fractures in elderly men: Mr OS Sweden. J Bone Miner Res 2010, 25(5):1010-1016.

43. Law MR, Hackshaw AK: A meta-analysis of cigarette smoking, bone mineral density and risk of hip fracture: recognition of a major effect. BMJ 1997, 315(7112):841-846.

44. Higdon JV, Frei B: Coffee and health: a review of recent human research. Crit Rev Food Sci Nutr 2006, 46(2):101-123.

45. Kanis JA, Oden A, McCloskey EV, Johansson H, Wahl DA, Cooper C, on behalf of the IOF Working Group on Epidemiology and Quality of Life: A systematic review of hip fracture incidence and probability of fracture worldwide. Osteoporos Int 2012, 23(9):2239-2256.

doi:10.1186/1471-2474-13-173

Cite this article as: Määttä et al:: Lifestyle factors and site-specific risk of hip fracture in community dwelling older women - a 13-year prospective population-based cohort study. BMC Musculoskeletal Disorders 2012 13:173

\section{Submit your next manuscript to BioMed Central and take full advantage of:}

- Convenient online submission

- Thorough peer review

- No space constraints or color figure charges

- Immediate publication on acceptance

- Inclusion in PubMed, CAS, Scopus and Google Scholar

- Research which is freely available for redistribution 